Sir: Further to the recent correspondence, I would totally support the views expressed by $\mathrm{Dr}$ Mathew (Psychiatric Bulletin, 1993, 17, 627).

Hypnosis is neither alternative nor substitute nor 'second line' therapy. Hypnosis is additional therapy useful in that large area of illnesses which fall within the category of the neuroses, as well as for a certain limited number of problems for which drugs are usually unavailable or unsuitable (Waxman, 1980).

The sooner that psychiatrists and indeed the College accepts this fact, the better for the profession - as well as for our patients.

WAXMaN, D. (1980) Clinical applications of hypnosis in psychiatry, British Journal of Hospital Medicine, 456-463.

D. WAXMan, President, British Society of Medical and Dental Hypnosis, Metropolitan and South, and Vice President, Section of Hypnosis and Psychosomatic Medicine, Royal Society of Medicine, London WI

\section{The future of services for the chronically mentally ill: a priority case?}

Sir: Soni et al (Psychiatric Bulletin, 1993, 17, 582-585) touch upon areas of concern with which most clinicians would concur. However, an issue of equal concern is how the purchaser/ provider split affects the planning of psychiatric services. There are problems of communication. differences in perception about what makes a good service and financial constraints within which to deliver a service. Also, the role of consultants in the planning process has diminished and there is often inadequate consultation between planners and clinicians.

The Mental Illness Key Area Handbook from the Department of Health indicates clearly the different responsibilities and expectations of purchasers and providers. It serves as a good framework and looks appealing on paper but to translate it into a practical reality is another matter. Local purchasing strategy documents often omit or refer vaguely to issues of importance to providers.

With dispersal of long-stay patients with chronic mental illness from hospital into the community, their problems of living can be easily overlooked. Well resourced community facilities (residential, day care, community mental health teams) supported by good quality secondary services (adequate in-patient beds for acute care, specialised multidisciplinary rehabilitation care and high dependency units) delivered in an integrated manner can address the problem. But if the clinicians' role in the planning process is steamrolled by purchasers and financial constraint dictates developments, then the good intentions of the Health of the Nation document will remain hollow.

THAKOR MISTRY, South West Community Mental Health Team, The Cottage, 6 Simpson Street, Oldbury. West Midlands

\section{The Mental Health Act 1983 and people with learning disabilities}

A recent visit from the Mental Health Commissioners in Powys highlighted a dilemma. One commissioner alluded to "considering to place an informal person with severe learning disability and associated disturbed/disruptive behaviour on section 3 of the Mental Health Act so that protection could be offered in respect of consent to treatment with the antipsychotic medications required in order to control behaviour problems". This raises fundamental issues.

(a) Even if the informal patient (resident) is incapable of giving valid and informed consent, he or she is not actively refusing to take medication. The question of implied consent and duty of care are relevant here.

(b) Can a patient (resident) with severe learning disability who needs antipsychotic medication for behaviour problems, which are largely of nuisance in nature, be detained just to offer the protection for consent to treatment even if he or she does not fulfil the criteria of the Act for being diagnosed severely mentally impaired, 1.e. in the absence of abnormally aggressive or grossly irresponsible conduct and not a risk to self or others?

(c) There will be enormous repercussions for resettlement into 'ordinary facilities' in the community.

(d) This approach will label and stigmatise people against the principles of normalisation. Detention under the Mental Health Act 1983 inherently has serious connotations.

(e) How will the Act afford protection to these people with similar needs in the community in ordinary facilities?

(f) The issue of management of a resident who is prone to wandering or absconding is equally contentious and has not been dealt with adequately in the Act.

These issues are gaining importance in the light of heightening awareness of the rights of people with learning disabilities and are equally applicable in hospital and community situations.

H. M. VERMA, Brynhyfryd Hospital, Forden, near Welshpool, Powys SY21 8NW 